\title{
Correlation between Gross Motor Function Classification and Participation of Children and Youth with Cerebral Palsy in Leisure Activities
}

\section{Madineh Hassani*}

M.A of Occupational Therapy, Occupational Therapy Center, Paveh, Iran

*Corresponding Author: Madineh Hassani, M.A of Occupational Therapy, Occupational Therapy Center, Paveh, Iran.

Received: October 09, 2019; Published: October 31, 2019

\begin{abstract}
Introduction: Participation in leisure and recreational activities is essential for health development of all children and associated with their well-being. The purpose of this study was Investigate the correlation between Gross Motor Function Classification System and participation of children and youth with cerebral palsy in leisure activities.

Materials and Methods: In this cross-sectional study, 60 children and youth with cerebral palsy (mean age: $12 \mathrm{y} 9 \mathrm{mo}$ ) from special education school through. non-probability convenience sampling were selected. Gross Motor Function was evaluated with the Gross Motor Function Classification System (GMFCS) and Participation with the Children's Assessment of Participation and Enjoyment (CAPE). The data were analyzed by Spss17.

Results: There were not significant correlation between cerebral palsy's participation and GMFCS in diversity and intensity for overall activities ( $\mathrm{p}>0.05)$. Also correlation was not significant between variables of "whom", "were" and "enjoyment" of participation with GMFCS ( $\mathrm{p}>0.05)$.in other words GMFCS was not impact on participation of children and youth with cerebral palsy in leisure activities.

Conclusion: Correlation was not significant between GMFCS and participation patterns of children and youth with cerebral palsy in leisure activities. Knowledge about participation of cerebral palsy children can help to health care professional to establish interventions that fit with children's preferences and can promote their health and participation.

Keywords: Participation; Cerebral Palsy; GMFCS; Leisure Activities
\end{abstract}

\section{Introduction}

Participation in the daily Occupations is fundamental for all humans. As the World Health Organization implied, participation has a positive impact on the health and well-being of the individual [1]. The occupational roles of childhood require children to develop personal independence, become productive and participate in play or recreational activities [2]. Engaging in leisure activities for growing skills, competencies social efficiency, and becoming socially with friends and discovery of personal interests and the pleasant life is essential $[3,4]$. Due to motor defects. The ability of children with cerebral palsy be affected for movement, communication, problem solving, socialization, and they may be at risk for less participation in recreational activities [5,6].

Identify the determinants of participation in order to develop strategies to promote health and the beginning of the policy that children Cerebral palsy makes enable to participate more in society and get more satisfaction in life, it has great importance [6]. Based on the participation model of king (2003) for physical dis- able children, factors that affect the participation of these children in recreational and leisure activities, including physical social and attitudinal aspects of the environment, performance, consideration of family priorities and impairments related to child, and activity limitations [5]. Palisano., et al. (2011) In a cohort study, examined the participation of 205 adolescents with Cerebral Palsy 21-13 Years old by test, and the results showed that the GMECŚ s level doeś t have a direct impact on intensity of participation [7] But Or$\operatorname{lin}^{1}$ and his colleagues (2009) studied the participation of 291 children Cerebral palsy (6 to 12 years) teens 209 and cerebral palsy (13 to 21 years) of 6 children Cerebral Palsy School in the United States *The results indicated Children and adolescents who had GMECŚ s level I, they had the largest participation [8].

There are insufficient information in this area that motor problems, how and to what extent affect the participation of children with cerebral palsy in daily life. Although Gross Motor Function are measured generally in children with cerebral palsy but the correct observation and measurement of motor skills is difficult for

${ }^{1}$ Orlin 
the therapists. Cerebral palsy children may have similar levels of damage but their participation may vary in life situations due to differences in performance level and social areas [9]. Considering the focus of rehabilitation therapy is to help maximize abilities and competencies for disable individuals, Therefore, identification of factors that affect the person's activities and participation in the situations of life is very important. The objective of this study investigate of the relationship between Gross Motor Function classification system and participation of children and youth with cerebral palsy in leisure activities.

\section{Method}

\section{Participants}

In this Cross-sectional study 60 children and teenager with Cerebral palsy 7-21 years from special schools for physical disabled children Who were eligible for inclusion in the study, were selected through convenience sampling method. inclusion criteria for Children's cerebral Palsy include: 1) Education in schools i for physical disabled children, 2) having diagnosis of cerebral palsy according to a physician of the neurology, 3)having a normal or border IQ 4) lack of any co-morbidity including pervasive developmental disorder, learning disorder, and psychiatric disorders, according to a report appearing in the school file, and 5) lack of severe communication problems and the ability to understand the concepts of English and test items and 6)lack of chronic diseases and mental disorders, according to the school records. They were excluded if they did not cooperate in the complete of the questionnaire of the test.

\section{Procedures and instruments}

This study was cross-sectional research In, this study, the children's participation was measured using the Children's Assessment of Participation and Enjoyment (CAPE) test. This test was developed to evaluate the participation of the children with disabilities or without disabilities aged 6 to 21 years in everyday activities out of mandated school activities. After this study was approved by the ethics committee of the Ministry of Education and the written informed consent was signed by the parents the children and youth could participate in the study.

The examiner initially determined the child's level gross motor function according to GMFCS (Gross Motor Function Classification System) via observation. The procedure of data collection was done through completing CAPE forms and cards during interviews with children by therapists. On each card there was a picture of the activity accompanied by a phrase or word which described that activity. Moreover, therapists used rest time during interview if necessary. The child was asked to rate the way she/he had performed the activity in the past 4 months on a 7 -point scale (from 1 to 7 ), and the enjoyment of doing it on a 5- point scale (from 1 to 5). Accordingly, five types of scoring were obtained from the test [11]:
1. The diversity of participation (diversity): Does the child perform the activity or not?

2. The intensity of participation (intensity): How many times does the child do the activity?

3. The enjoyment of participation (enjoyment): How much does the child enjoy doing the activity?

4. The role of others in participation (with whom): With whom does the child often do the activity?

5. The place of Participation (where): Where does the child often do the activity?

This test consists of 55 activities, and based on the principal component analysis, the priorities of the children were divided into 5 types of activities including recreational, physical, social, skill-based, and self-help activities. The reliability and validity of this test were evaluated for the first time in Canada in by King., et al. who conducted the study on 427 children with physical disabilities. The estimated reliability for the CAPE test in terms of the diversity of participation was 0.75 to 0.93 , and the validity was also checked $[11,12]$. The reliability and validity of this test Iran was implemented by Amiryan., et al. The results showed discriminant validity of the items for this questionnaire is appropriate. Kronbach Alfa 86/0 and the correlation coefficient in the class Obtained 75.0. The results represent high reliability and validity of the Persian version of this test [13].

\section{Statistical analyses}

For data analysis, SPSS 17 software was utilized. The descriptive statistics (mean, standard deviation, etc.) were used to describe the level of children's participation and enjoyment for all of the items in the CAPE test. The Spearman correlation test was conducted to explore the Correlation between GMFCS and items of participation

\section{Results}

In this study, The levels of participation of 60 school-age children and youth with cerebral palsy were examined. The demographic characteristics of the people with cerebral palsy are shown in table 1 . Out of 53 activities, the average number of activities (the diversity of participation) done by People with cerebral palsy was 21.9 activities The results of the spearman correlation indicated There was no the significant correlation between Diversity of participation and GMFCS levels Also, the relationship between intensity of participation where whom, and enjoyment With the GMFCS levels were not statistically significant. In other words, the GMFCS levels has not affected the participation of the people with cerebral palsy (Table 2). 


\begin{tabular}{|c|c|c|c|}
\hline \multirow[t]{2}{*}{ Demographic characteristics } & \multirow[t]{2}{*}{ Items } & \multicolumn{2}{|c|}{ People have cerebral palsy. } \\
\hline & & Abundance percent & Average \\
\hline Age & & & $12 \mathrm{x}$ and 9 Magda \\
\hline \multirow{2}{*}{ Sex } & Girl & 50 & \\
\hline & Boy & 50 & \\
\hline \multirow{5}{*}{ and level GMFCS } & Level 1 & $3 / 18$ & \\
\hline & Level 2 & $7 / 21$ & \\
\hline & Level 3 & $3 / 28$ & \\
\hline & Level 4 & $7 / 16$ & \\
\hline & Level 5 & 15 & \\
\hline \multirow{4}{*}{ Vision problems } & No problem & $7 / 46$ & \\
\hline & Strabismus & $7 / 16$ & \\
\hline & Low damage (rings glasses) & $3 / 33$ & \\
\hline & Unknown & $3 / 3$ & \\
\hline \multirow{3}{*}{ Hearing problems } & No problem & 90 & \\
\hline & Deaf & 0 & \\
\hline & Use of audio assistive devices & 10 & \\
\hline \multirow{4}{*}{ Pronunciation problems } & No problem & $7 / 46$ & \\
\hline & No talking & $7 / 6$ & \\
\hline & Low damage & 40 & \\
\hline & Unknown & $7 / 6$ & \\
\hline
\end{tabular}

Table 1: Descriptive information for children cerebral palsy.

\begin{tabular}{|l|c|c|}
\hline \multicolumn{1}{|c|}{ Variables } & $\begin{array}{c}\text { Correlation } \\
\text { coefficient }\end{array}$ & $\begin{array}{c}\text { There was a great } \\
\text { level of }\end{array}$ \\
\hline Diversity & $181 / 0-$ & $166 / 0$ \\
\hline Intensity & $236 / 0-$ & $069 / 0$ \\
\hline Whom & $033 / 0$ & $803 / 0$ \\
\hline Where & $056 / 0-$ & $674 / 0$ \\
\hline Enjoyment & $242 / 0-$ & $062 / 0$ \\
\hline Number of persons & 60 & 60 \\
\hline
\end{tabular}

Table 2: Sperm Link Test Results Summary Relationship between partnership and level GMFCS.

\section{Discussion}

The significant relationship between the number of activities carried out by children and adolescents and the levels's Gross motor function of the cerebral palsy (GMFCS) were not found, In other words, the GMFCS levels has not affected the diversity of participation. This finding was not in line with the findings of the Orlin., et al. (2010) study on the 500 people with cerebral palsy 6 to 21 years old which were conducted in the United States, and Longer., et al. (2013) study in Spain which have been conducting in 199 children with cerebral palsy 8- 18 aged [8,14]. This finding can be due to low sample size of this study. But It was aligned with the finding of the prospective cohort study which done by Palisano., et al. (2011),
Who concluded GMFCS levels had an indirect impact on the participation of children and youth with cerebral palsy [7].

Also there was not the significant correlation between intensity of participation and the levels of GMFCS statistically, This finding supports the results of Longo (2012) study and Orlin study (2009) in the United States $[8,14]$.

Regarding the Enjoyment of participation, the relationship between the GMFCŚ s level and Enjoyment of participation, were not also statistically significant that it was aligned with the finding of the Longo (2013) study and Majnemer., et al. (2008) study In Canada $[6,14]$.

In this study children and youth with cerebral palsy had low scores of the diversity and intensity and their scores of enjoyment were high, This result is in line with the results of Longo (2013) study and other studies that compared the participation of children cerebral palsy and physical disability with their normal peers were done $[4,6,14-17]$. This result may indicate that the severity of motor disability in people with cerebral palsy cannot be an important predictor of the level of satisfaction and pleasure associated with participation in leisure activities. So, the low scores of diversity and intensity of participation do not necessarily mean that the partici- 
pation of these people in leisure activities is limited, but a child may have a successful participation in fewer activities, while he really enjoys doing them. Some of the reasons of the low intensity of participation of the children with cerebral palsy can be found in the problems related to handling and transfer by their parents and the cost of these children's participation in the leisure activities.

There was no significant correlation between the level of GMFCS with the place of participation (where) and the attendance of others in participation(whom), meaning GMFCS level had no significant effect on the whom and where, which was consistent with the results of the study Hassani., et al. (2013), which examined the participation of 30 children with cerebral palsy [18]. This relationship has not yet been reviewed in other studies. In the study of Hassani., et al. (2013) and Engle-yeger., et al. (2009) that the participation of children cerebral palsy was compared to their normal peers, the differences between the two groups of cerebral palsy and healthy developing peers were significant for where and whom [17,18]; In comparison with the normal children, the children with cerebral palsy preferred to perform the activities by themselves, which can be owing to the fact that their normal peers would rather cooperate with their friends in performing these activities; while the physical restrictions of the children with $\mathrm{CP}$ may impede them from doing various activities in different environments. Therefore, they perform the activities in the environments which are adapted based on their disabilities such as home and schools [17,19]. Children with disabilities and their families encounter the contradictions of the development of the emotional independence and an independent identity, while these children are still physically dependent on their parents or caregivers [20].

Participation in out-of-school time plays an important role in the health, welfare, and development of children [3,21]. The participation of the children with physical disabilities in daily activities is an influential factor in gaining independence in adulthood [22]. ICF considers participation as the result of interaction between person and the social and physical environment. The Primary goal of rehabilitation for school -age children with cerebral palsy is independence in personal care, mobility, and being productive [21]. Occupational therapy has a unique role in the development and participation of people with and without disabilities and promoting their health and well-being. hence, identification of effective factors in the participation of children with cerebral palsy is important for effectiveness of rehabilitation programs.

\section{Conclusion}

Based on the results, it can be declared that the GMFCŚ s levels of children's cerebral palsy can not affect their participation. Given that the ultimate purpose of the occupational therapy's intervention for the children with disabilities is to enable them to participate in the purposeful childhood activities and Regarding the great importance of leisure participation in this activities, the understanding of the factors that affect participation in the situations of life can pave the way for the occupational therapists and families to design activities and treatments tailored to the needs of the children and promote their health and participation.

\section{Acknowledgments}

This article is part of an approved project in Tehran University of Medical Sciences. We wish to thank our research coordinator, Dr Hassani Mehraban and data collector Mrs Rameani efforts in coordinating this project. We are grateful to the families and children who participated in this study. Thanks are due to occupational therapists Mrs Saeedloo, Mrs Meamari and Minister in special schools for physical disabled children.

\section{Bibliography}

1. Law M. "Participation in the occupations of everyday life". The American Journal of Occupational Therapy 56 (2002): 640.

2. Rodger S and Ziviani J. "Occupational therapy with children: Understanding children's occupations and enabling participation". Oxford: Backwell Publishing (2007).

3. Simpkins SD., et al. "Predicting participation and outcomes in out-of-school activities: Similarities and differences across social ecologies". New Directions for Youth Development (2005): 51-69.

4. Hassani MA., et al. "The Comparison of Participation in SchoolAged Cerebral Palsy Children and Normal Peers: A Preliminary Study". Iranian journal of Pediatric 26 (2016): 1-7.

5. King G., et al. "A conceptual model of the factors affecting the recreation and leisure participation of children with disabilities". Physical and Occupational Therapy in Pediatrics 23 (2003): 63-90.

6. Majnemer A., et al. "Participation and enjoyment of leisure activities in school-aged children with cerebral palsy". Developmental Medicine and Child Neurology 50 (2008): 751-758.

7. Palisano RJ., et al. "Determinants of Intensity of Participation in Leisure and Recreational Activities by Youth With Cerebral Palsy". Archives of Physical Medicine and Rehabilitation 92 (2011): 1468-1476.

8. Orlin MN., et al. "Participation in home, extracurricular, and community activities among children and young people with cerebral palsy". Developmental Medicine and Child Neurology 52 (2010): 160-166.

9. Kerr C., et al. "The relationship between gross motor function and participation restriction in children with cerebral palsy: an exploratory analysis". Child: Care, Health and Development 33 (2006): 22-27. 
10. Leila Dehghan Hd and Hossein Bagheri. GMFCS - E and R Gross Motor Function Classification System Expanded and Revised (2009).

11. King GA. CAPE/PAC Manual: Children's Assessment of Participation and Enjoyment and Preferences for Activities of Children: PsychCorp (2004).

12. King G., et al. "Measuring children's participation in recreation and leisure activities: construct validation of the CAPE and PAC". Child: Care, Health and Development 33 (2006): 28-39.

13. Amirian Sr. "Validity and reliability of children's assessment of participation and enjoyment for people with disability aged 7-17 years old". Rehabilitation Medicine 3 (2014).

14. Longo E., et al. "Patterns and predictors of participation in leisure activities outside of school in children and adolescents with Cerebral Palsy". Research in Developmental Disabilities 34 (2013): 266-275.

15. Imms C., et al. "Diversity of participation in children with cerebral palsy". Developmental Medicine and Child Neurology 50.5 (2008): 363-369.

16. King G., et al. "Predictors of change over time in the activity participation of children and youth with physical disabilities". Children's Health Care 38 (2009): 321-351.

17. Angel Yeger B., et al. "Differences in patterns of participation between youths with cerebral palsy and typically developing peers". The American Journal of Occupational Therapy 63 (2009): 96-104.

18. Hassani M. "Comparison of participation between children with cerebral palsy and typically developing peers 8-14 years old in leisure activities". Modern Rehabilitation 7 (2013).

19. Law M., et al. "Patterns of participation in recreational and leisure activities among children with complex physical disabilities". Developmental Medicine and Child Neurology 48 (2006): 337-342.

20. Rogers SL. “Common conditions that influence children's participation”. Occupational therapy for children 5 (2005).

21. Forsyth R and Jarvis S. "Participation in childhood". Child: Care, Health and Development 28 (2002): 277-279.

22. Blum RW., et al. "Family and peer issues among adolescents with spina bifida and cerebral palsy". Pediatrics 88 (1991): 280-285.

Volume 2 Issue 11 November 2019

(C) All rights are reserved by Madineh Hassani. 